\title{
Effect of milk production on reproductive performance in dairy herds
}

\author{
R. Rearte, ${ }^{*} †$ S. J. LeBlanc, $\ddagger$ S. G. Corva, ${ }^{*}$ R. L. de la Sota,†§ I. M. Lacau-Mengido, †\# and M. J. Giuliodorill ${ }^{1}$ \\ *Cátedra de Higiene, Epidemiología y Salud Pública, Facultad de Ciencias Veterinarias-Universidad Nacional de La Plata, La Plata, B1900AVW, \\ Argentina \\ †Consejo Nacional de Investigaciones Científicas y Técnicas (CONICET), Buenos Aires, C1033AAJ, Argentina \\ ‡Department of Population Medicine, University of Guelph, Guelph, Ontario, Canada N1G 2W1 \\ §Cátedra y Servicio de Reproducción Animal, Facultad de Ciencias Veterinarias-Universidad Nacional de La Plata, La Plata, B1900AVW, \\ Argentina \\ \#Instituto de Biología y Medicina Experimental-Consejo Nacional de Investigaciones Científicas y Técnicas, Buenos Aires, C1428ADN, Argentina \\ ॥Cátedra de Fisiología, Facultad de Ciencias Veterinarias-Universidad Nacional de La Plata, La Plata, B1900AVW, Argentina
}

\begin{abstract}
The objective of the present study was to assess the relationship between individual cow milk yield and fertility, accounting for the contextual effect of the herd. A data set including 657,968 lactations from 677 dairy herds in Argentina from 2001 to 2012 was used. The odds of pregnancy by $100 \mathrm{~d}$ in milk (DIM) were assessed by a multilevel logistic model (with cow as the first and herd as the second hierarchical level), and time to pregnancy was assessed by a proportional hazards regression model. Multilevel logistic models included the fixed effects of milk yield by 80 DIM, parity, year, and calving season at cow level and quartiles of herd milk yield by 80 DIM as a contextual effect. The proportional hazards model included the effect of daily cow-level milk yield as time-dependent variable, with milk yield at herd level as the stratification variable. Cows producing 1 standard deviation over the mean milk yield of their herd had 1.3 percentage point lower pregnancy by 100 DIM (from 31.4 to $30.1 \%$; odds ratio $=0.942$ ) when in herds in the top quartile of milk yield, whereas they increased 0.5 percentage points (from 27.9 to $28.4 \%$ ) when in herds in the lowest quartile of milk yield. Only $4 \%$ of the observed variation in pregnancy by 100 DIM was explained by the random effect of the herd. Similarly, cows producing 1 standard deviation $(8$ $\mathrm{kg} / \mathrm{d})$ greater than the herd mean daily milk had $1.3 \%$ lower hazard of pregnancy (hazard ratio $=0.987$ ) at 63 DIM in herds in the top quartile of milk yield, whereas they had $14.8 \%$ higher hazard (hazard ratio $=1.148$ )
\end{abstract}

Received September 6, 2017.

Accepted April 16, 2018.

${ }^{1}$ Corresponding author: mauriciog1969@gmail.com in herds in the lowest quartile of milk yield. The magnitude of the negative association between the cow's daily milk yield and the hazard of pregnancy increased with DIM. In conclusion, the relationship between milk yield and reproductive performance is statistically significant, but the effect size is practically small and is modulated by herd production level.

Key words: milk yield, reproductive performance, contextual effect, multilevel model

\section{INTRODUCTION}

The dairy industry in Argentina has undergone substantial changes during the last 25 yr. Traditionally, the dairy industry has heavily relied on grass for milk production, but in the 1990s an important intensification took place. As a consequence of that process, the national milk production per year increased from 6,000 to 10,000 million $\mathrm{kg}$, whereas the number of herds decreased from 30,141 to 15,000 and the average herd size increased from 67 to 134 cows. This improvement in productivity was accompanied by an increase in stocking rate per hectare, whereas the average individual milk yield increased only from 8.5 to $11.5 \mathrm{~kg} / \mathrm{d}$. Conversely, between 2002 and 2012 the average individual milk yield increased from 11.5 to $18.5 \mathrm{~kg} / \mathrm{d}$, whereas the total dairy cow population decreased from 2,005,000 to 1,748,000 (Parellada and Schilder, 1999; Taverna, 2013). This intensification in the use of agricultural resources during recent decades, a worldwide trend, has led to an increase in productivity (FAO, 2005). During the same period, there was a decline in some measures of the fertility of dairy cows (Lucy, 2001; Butler, 2003; Melendez and Pinedo, 2007; Piccardi et al., 2013). Therefore, some researchers have proposed an antagonistic relationship between milk yield and fertility (Lucy, 2001; Butler, 2003). Many studies have addressed this controversial topic with inconsistent approaches and results. Some 
Table 1. Descriptive data about number of herds, dairy cows per herd, milk yield at 305 DIM, and pregnancy by 100 DIM for the 12-yr period (2001-2012) used in the study ${ }^{1}$

\begin{tabular}{lcccc}
\hline Year & $\begin{array}{c}\text { Herds } \\
\text { (no.) }\end{array}$ & $\begin{array}{c}\text { Cows }^{2} \text { Mean } \\
(\text { minimum-maximum })\end{array}$ & $\begin{array}{c}\text { Milk305 } \\
\text { Median (IQR) }\end{array}$ & $\begin{array}{c}\text { PREG100 (\%) } \\
\text { Median (IQR) }\end{array}$ \\
\hline 2001 & 163 & $141(26-660)$ & $5,950(5,091-6,911)$ & $33(26-41)$ \\
2002 & 175 & $145(26-714)$ & $5,767(4,961-6,738)$ & $31(23-40)$ \\
2003 & 271 & $138(26-802)$ & $6,390(5,520-7,378)$ & $30(23-38)$ \\
2004 & 320 & $151(27-917)$ & $6,923(5,969-7,939)$ & $32(23-41)$ \\
2005 & 397 & $138(26-987)$ & $7,140(6,158-8,180)$ & $31(25-40)$ \\
2006 & 463 & $147(26-1,221)$ & $7,189(6,211-8,290)$ & $30(25-40)$ \\
2007 & 503 & $148(26-1,267)$ & $7,105(6,129-8,186)$ & $28(20-35)$ \\
2008 & 530 & $155(26-1,111)$ & $7,360(6,339-8,493)$ & $28(20-37)$ \\
2009 & 522 & $167(26-1,339)$ & $7,417(6,423-8,541)$ & $28(19-34)$ \\
2010 & 519 & $172(27-1,506)$ & $7,910(6,832-9,116)$ & $30(23-36)$ \\
2011 & 526 & $186(26-1,648)$ & $8,153(7,089-9,351)$ & $29(21-35)$ \\
2012 & 476 & $188(27-1,673)$ & $7,697(6,695-8,835)$ & $27(20-34)$ \\
\hline
\end{tabular}

${ }^{1}$ The mean number of lactations per cow was 2.03 (range $=1-11$ ), and the mean number of years per herd in the study was 6.89 (range $=1-12$ ).

${ }^{2}$ Number of lactations that commenced per herd per year.

${ }^{3}$ Raw milk yield in 305 DIM per herd per year, expressed in kilograms; median and interquartile range (IQR; 25 th to 75 th percentile).

${ }^{4}$ Percentage of cows pregnant by 100 DIM per herd per year; median and interquartile range (IQR; 25 th to 75 th percentile).

found some negative associations (Eicker et al., 1996; Gröhn and Rajala-Schultz, 2000; Lucy, 2001; Butler, 2003; Melendez and Pinedo, 2007; Madouasse et al., 2010; Piccardi et al., 2013), whereas others reported a positive relationship (Rajala-Schultz et al., 2001; Campbell et al., 2009; Cook and Green, 2016). These inconsistencies could be the result of biased indicators (i.e., measures of production and reproduction) used (LeBlanc, 2010), selection bias due to management decisions in studies performed in commercial dairy herds (Morton, 2006), or the way multilevel data were handled by researchers (Bello et al., 2012). Multilevel models allow us to assess contextual effects by including a higher-level predictor that represents the effect of the context or group to which individuals belong (Snijders and Bosker, 2012). We can use this analysis to separately estimate the relationship between milk yield and reproductive performance at cow and herd levels. The relationship at the herd level (the herd contextual effect) may differ in magnitude and even direction from the relationship at the cow level.

Our working hypothesis was that milk yield and reproductive performance in dairy cows are not necessarily antagonistic and that this relationship is influenced by the effect of the herd. Hence, the main objectives of this study were to assess the relationship of cow-level milk yield with reproductive performance and whether that association changes with the level of herd milk production and to estimate the magnitude of herd contextual effect. An additional objective was to estimate the trend of indicators of reproductive performance over time in Argentinean dairy herds.

\section{MATERIALS AND METHODS}

\section{Data Set}

A retrospective longitudinal study was conducted using a data set including dairy herds from the province of Buenos Aires, Argentina. Production, reproduction, and health information was gathered by the official dairy herd improvement association (Asociación de la Regional Pampeana de Entidades de Control Lechero). Data for all the lactations ("cow" is used to mean "lactation") started between January 1, 2001, and December 31, 2012 (1,573,593 cows from 862 herds), were extracted from commercial software (DIRSA S.A., Gonnet, Argentina). Descriptive data about herd numbers, herd size, herd's milk yield at 305 DIM, and herd's pregnancy rate by 100 DIM are shown in Table 1 and Figure 1, and descriptive data about pregnancy rate per 21-d period for all the cows included in the study are shown in Figure 2.

\section{Lactation and Herd Selection}

Only lactations with valid reproductive and milk production data were included in the study. Lactations were considered as having valid reproductive records when they met all the following criteria: (1) they had at least 1 AI recorded; (2) for lactations with a record of a subsequent calving, it was required that they had a recorded AI between 260 and $290 \mathrm{~d}$ before that new calving; and (3) cows with no record of new calving but with a positive pregnancy diagnosis were considered 


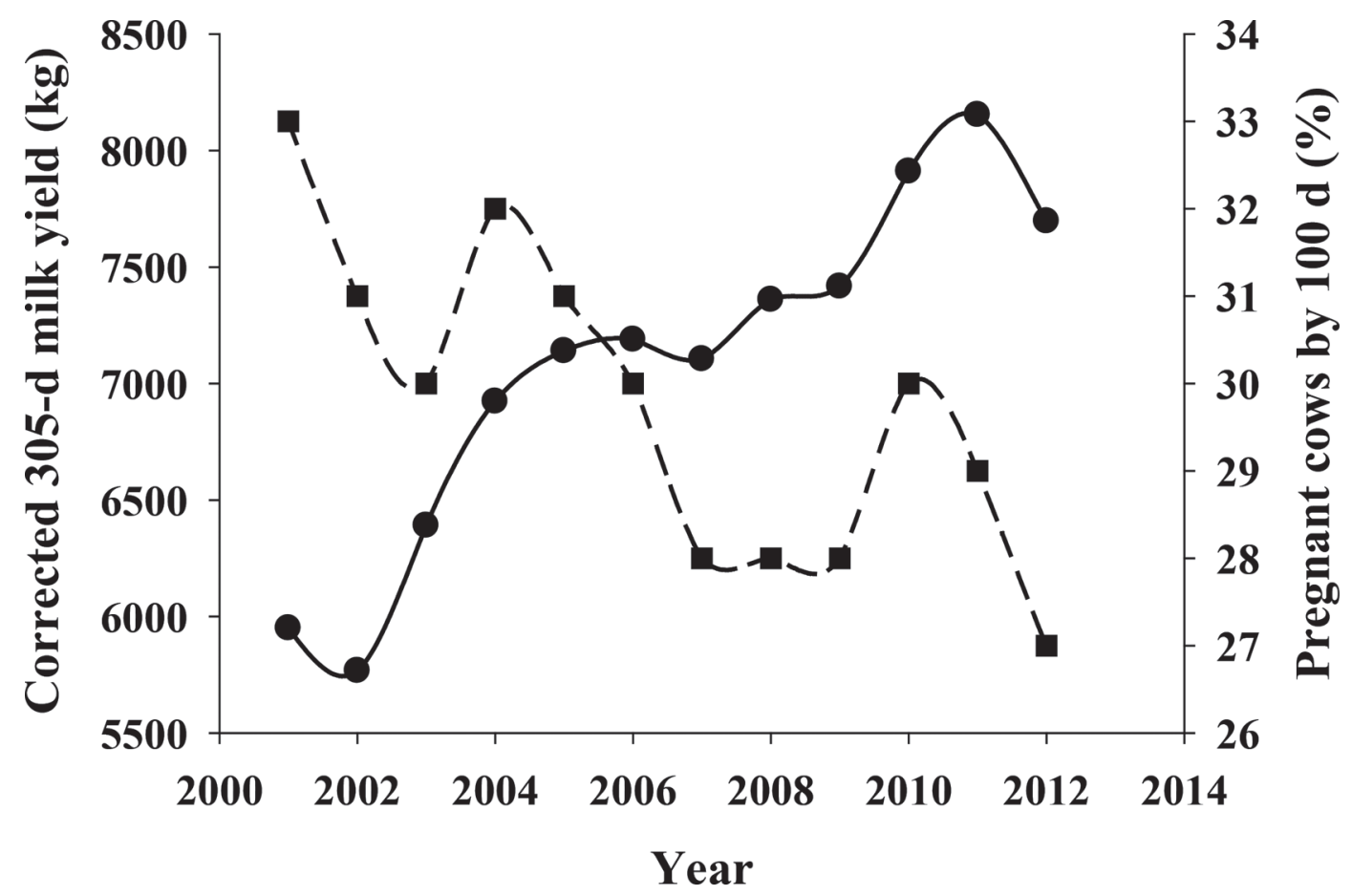

Figure 1. Herd median corrected 305-d milk yield mean (•) and proportion of cows pregnant by 100 d (ם) over a 12-yr period (2001-2012) in 677 dairy herds from Buenos Aires Province, Argentina.

as valid only if they had a record of culling, sale, or death after the pregnancy diagnosis. Otherwise, these lactations were not considered as having a valid reproductive record. Lactations were considered as having valid milk production records when they had at least 2

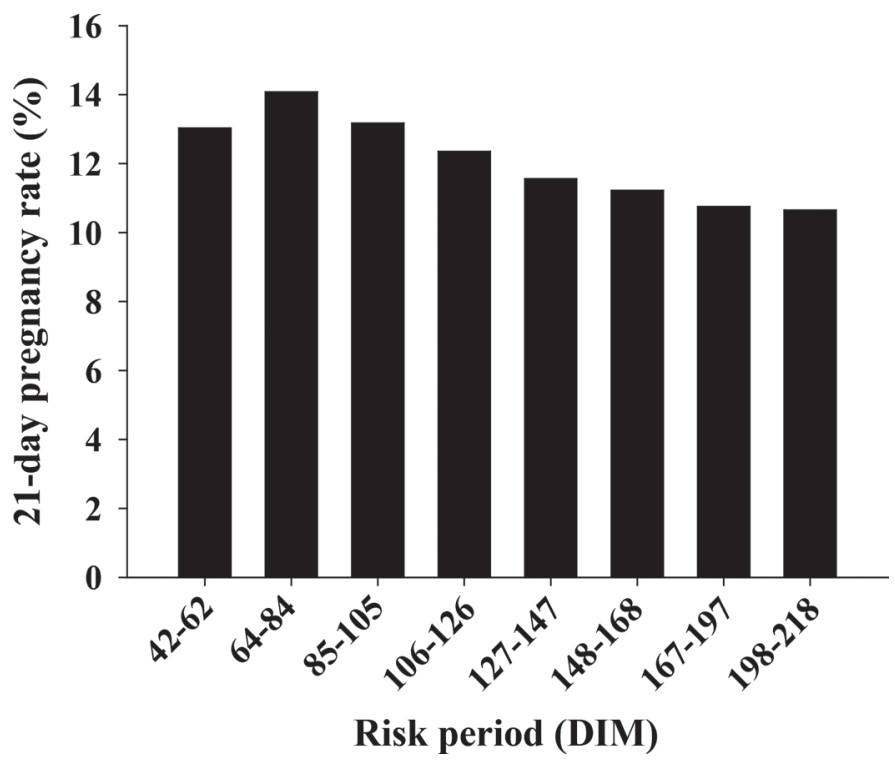

Figure 2. Probability of pregnancy per 21-d period for 657,968 lactations from 677 dairy herds located in Buenos Aires Province, Argentina, over a 12-yr period (2001-2012). monthly milk tests (with fat and protein) a maximum of $40 \mathrm{~d}$ apart by 80 DIM. Also, herd-year had to have at least $50 \%$ of cows with valid reproduction and milk production records to be included in the study. A set of 657,968 out of $1,576,593$ cows from 677 out of 862 herds was included in the statistical analysis. A flowchart with data validation is shown in Figure 3.

\section{Data Management}

Measures of milk production and reproductive performance were calculated as follows. For all the cows having a recorded calving, pregnancy date was defined as the date of last service before that parturition. For all the cows having a positive pregnancy diagnosis but without a record of calving, because they were culled or died after that positive pregnancy diagnosis, the date of last service was used to define their pregnancy date. Pregnancy risk period and pregnancy by 100 DIM (PREG100; yes or no) were calculated to assess reproductive performance. The pregnancy risk period was defined as the interval from calving to successful AI for pregnant cows or the interval from parturition to last service for nonpregnant cows. For descriptive purposes, pregnancy per 21-d period was estimated as all cows pregnant every 21-d period after the voluntary waiting period divided by all the nonpregnant cows at risk of pregnancy in the same periods (Figure 2). The 


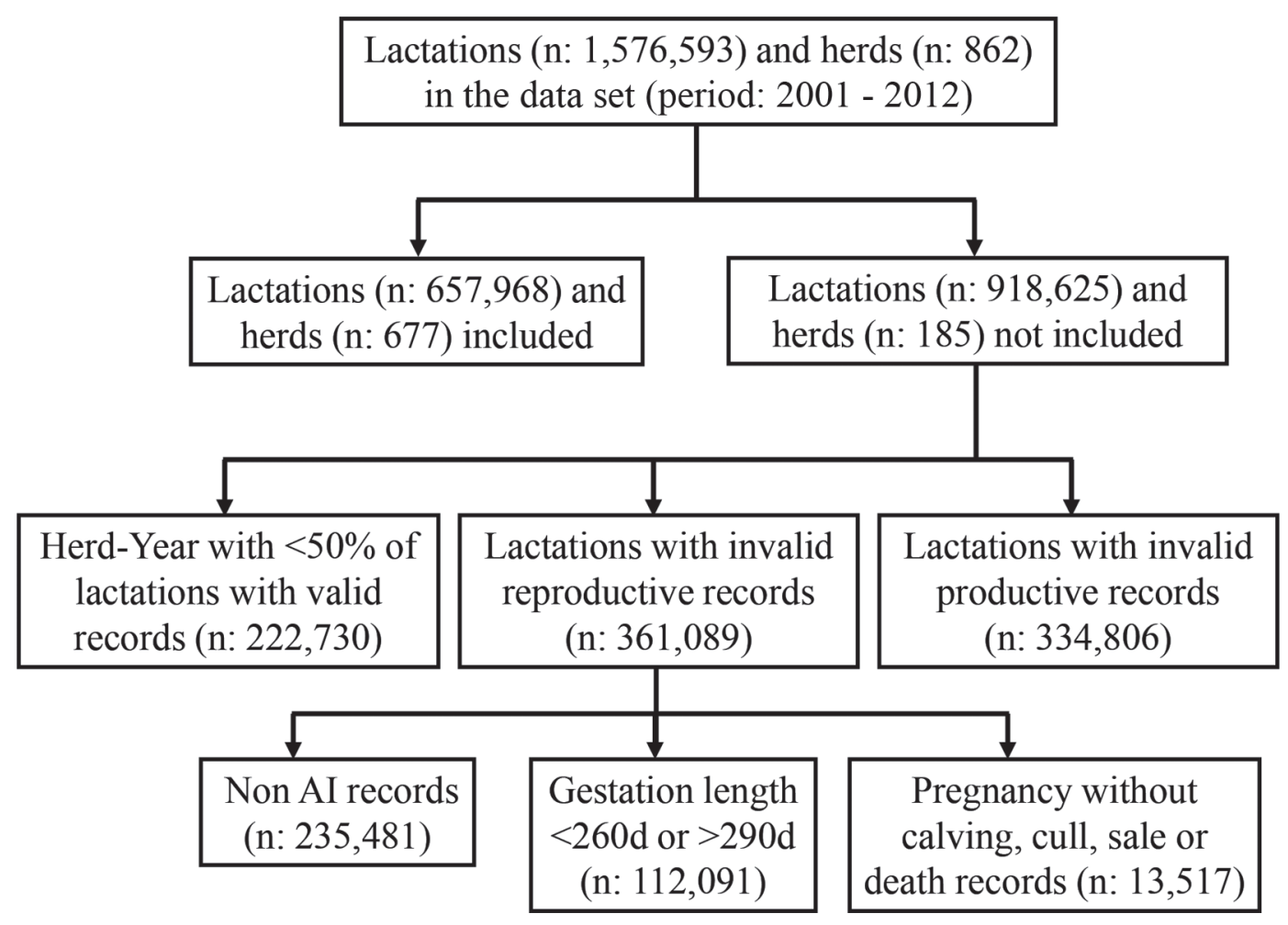

Figure 3. Flowchart showing validation of a data set containing production and reproduction records over a 12-yr period (2001-2012) from 1,576,593 lactations from 862 dairy herds located in Buenos Aires Province, Argentina. The data set was validated in the following order: (1) invalid reproductive records, (2) invalid productive records, and (3) invalid herd-year records. To be considered valid, a record must meet all the criteria. Reproductive records were validated in the following order: (1) non-AI records, (2) gestation length, and (3) pregnancy without calving, cull, sale, or death records.

voluntary waiting period was defined as the DIM by which $10 \%$ of cows in the herd-year had received their first insemination (Miller et al., 2007). Calving seasons (southern hemisphere) were summer (December 21 to March 20), fall (March 21 to June 20), winter (June 21 to September 20), and spring (September 21 to December 20). The cumulative raw milk yield (in $\mathrm{kg}$ ) by 80 DIM (CM80) was estimated by the test interval method (Sargent et al., 1968) for all cows having at least 2 monthly milk tests by 80 DIM (with fat and protein percentages measured with a mid-infrared instrument; ISO 9622:99; ISO, 1999). For each herd-year the mean CM80 for all the cows calving each calendar year in the same herd was estimated and named HM80. Then, HM80 was divided into quartiles. Finally, CM80 was centered on HM80 and expressed as standard deviation from their particular herd-year mean.

The total net energy secreted in milk by 80 DIM (CE80) was estimated with the following formula: $[(0.038 \times \mathrm{g}$ of crude fat $+0.024 \times \mathrm{g}$ of $\mathrm{CP}+0.017)$ $\times \mathrm{kg}$ of milk]/3.14 (RAP, 1999). For every herd-year the mean CE 80 and herd milk energy output by 80 DIM (HE80) for all the cows calving that year in the same herd were estimated. Then, HE80 was divided into quartiles. Finally, CE80 was centered on HE80 and expressed as standard deviation from their particular herd-year mean.

\section{Statistical Analysis}

Two multilevel logistic regression models were fitted to predict the probability of PREG100 by using MLwin software (Rasbash et al., 2009). In model 1, CM80 (cow level), HM80 (herd level), and their cross-level interaction were forced to remain in the final model to assess the cow level, herd contextual effect, and their interaction (Snijders and Bosker, 2012). Other cow-level covariates offered to the model were calving year (2001 to 2012), calving season (summer, fall, winter, spring), and parity $(1,2,3, \geq 4)$. The exclusion criterion for backward elimination method was that predictors were removed if 95\% credibility intervals for odds ratio (OR) included 1.00. In model 2, CM80 and HM80 were replaced by CE80, HE80, and their cross-level interaction. The rest of the predictors were the same. The random effect of herd was incorporated in the model to account for the correlation between cows within herds, considering the variance at cow level as $\pi^{2} / 3$, where $\pi=3.1416$, based 
on interpreting the binary variable PREG100 as the result of an underlying latent process with a continuous logistic distribution (Snijders and Bosker, 2012). The data also had other hierarchical structures as lactation into cow and cow into herd-year, but they were not taken into account because our 2-level model used was enough for the aims of this study. The initial model explorations were conducted by using penalized quasilikelihood, and the final models were constructed by using Markov chain Monte Carlo with Gibbs sampling, using default flat distributions for unbounded fixed effects $[\mathrm{p}(\beta) \propto 1]$ and a vague gamma distribution for random effect [ gamma distribution $(\alpha=0.001$, $\beta=0.001$ ); Rasbash et al., 2009]. Both Markov chain Monte Carlo models used a burn-in of 5,000 iterations, and the parameter estimations were based on a further 50,000 iterations, which was enough for good parameter estimation based on Raftery-Lewis and Brooks-Draper diagnostics. Parameters were considered statistically significant when $95 \%$ credibility intervals for OR did not include 1.00. Model fit was evaluated by graphical examination of Bayesian herd-level residuals (caterpillar plot of standardized residuals) and plotting the expected number of pregnant cows within each ascending decile of fitted values (summing the fitted proportions across all individuals falling in that decile) against the number of pregnant cows observed within that same decile (Green et al., 2004).

A Cox proportional hazard regression model was run with PROC PHREG (SAS, 2016) to assess the effect of cow daily milk yield on the hazard of pregnancy by 200 DIM at different levels of herd milk yield. For operational reasons (too computationally demanding), this model was fitted on a data subset of herds obtained with a clustered sampling design proportionally stratified by year, with herds acting as clusters. Therefore, for each year (stratum), the subset included all the lactations from randomly selected herd-years (clusters) that started their lactation in that year. The number of herds selected in each year $(\mathrm{n}=77)$ to ensure a precision of $1 \mathrm{~kg}$ in the estimated average of herd mean milk yield at first monthly milk test in each year was estimated with a $95 \%$ confidence interval and assuming a standard deviation of $4 \mathrm{~kg}$ in herd mean milk yield (WinEpi, 2006). Herds were randomly selected by using random number generation (Excel, Microsoft Corp., Redmond, WA). Therefore, the data subset had 94,593 cows belonging to 402 herds through the 12 -yr period.

Cows with a pregnancy risk period $<42$ DIM were left-censored. Open cows that were culled, died, or had a pregnancy risk period $<200$ DIM were right-censored on the day of their respective event. Cows with a pregnancy risk period $>200$ DIM were right-censored at 200 DIM. Then, monthly milk test day yield (MTDY) was included as a time-dependent covariate by using the counting process method of PROC PHREG, considering that cow milk yield stays constant through the period between 2 successive milk checks (Allison, 1995). Also, DIM and its interaction with MTDY were included in the model to test the proportional hazards assumption allowing the coefficients for MTDY to vary by DIM, and HM80 was considered as the stratification variable to allow that the shape of the hazard function is different for every quartile of HM80. The interaction between MTDY and HM80 was included in the Cox model to test whether the slope for the effect of MTDY on the hazard of pregnancy varied across quartiles of HM80 (Borucka, 2013). The daily hazard of pregnancy was estimated for an increase of 1 SD in MTDY (8 $\mathrm{kg}$; estimated from pooled MTDY) at the following time points: $63,84,105,126,147,168$, and 189 DIM. Other predictors included were calving year (2001 to 2012), calving season (summer, fall, winter, spring), and parity $(1,2,3, \geq 4)$. These variables stayed in the model if they had a significant effect on the hazard of pregnancy. The Efron approximation was used for handling ties in the data. The statistical significance of each independent variable was tested with a Wald test, with a robust sandwich estimate (Lin and Wei, 1989), to take into account the herd clustering effect. In addition, the same model was fitted with inclusion of the interaction of year by MTDY to test the repeatability through the years. Finally, a sensitivity analysis was performed to test the assumption of nonindependent censoring, supposing 2 extreme situations: first, assuming a complete positive correlation between rightcensoring and pregnancy so that all the right-censored cows were assumed as becoming pregnant at censoring time, and second, assuming a complete negative correlation between right-censoring and pregnancy so that all the right-censored cows before 200 DIM were recorded as if they were right-censored at 200 DIM.

\section{RESULTS}

The effects of CM80 and HM80, adjusted for each other, on the odds of PREG100 are shown in Table 2. Cow-level milk yield to 80 DIM had a conditional effect on PREG100 such that the odds of being pregnant in cows in the top quartile of HM80 decreased $5.8 \%$ when their CM80 increased $1 \mathrm{SD}$ over the mean of their herd-year $(\mathrm{OR}=0.942$; Table 2). The cross-level interaction between CM80 and HM80 also had an effect on PREG100, given that the increase of 1 SD in CM80 was accompanied by decreases in odds of PREG100 of 4.2 and $1.3 \%$ in cows from upper-middle and lowermiddle quartiles of HM80 $(\mathrm{OR}=0.958$ and 0.987, respectively; Table 2). Conversely, the same increase 
Table 2. Logistic model assessing the effect of milk yield to 80 DIM at cow and herd levels on the odds of pregnancy by 100 DIM for 657,968 lactations from 677 dairy herds located in Buenos Aires Province, Argentina, over a 12 -yr period $(2001-2012)^{1}$

\begin{tabular}{lcccc}
\hline Item & $\begin{array}{c}\text { PREG100 } \\
(\%)\end{array}$ & $\begin{array}{c}\mathrm{CM}^{2} 0^{3} \\
(\mathrm{~kg})\end{array}$ & $\begin{array}{c}\text { Odds } \\
\text { ratio }\end{array}$ & $\begin{array}{c}95 \% \text { Credibility } \\
\text { interval }\end{array}$ \\
\hline CM80 by HM80 & & & & \\
CM80 at top HM80 & & & $0.942^{5}$ & $0.938-0.945$ \\
CM80 at upper-middle HM80 & & & $0.958^{5}$ & $0.948-0.967$ \\
CM80 at lower-middle HM80 & & $1.029^{5}$ & $0.977-0.996$ \\
CM80 at bottom HM80 & & & & \\
HM80 & 31.4 & 2,490 & $1.017-1.040$ \\
Top & 30.1 & 2,160 & $0.955^{5}$ & \\
Upper middle & 29.9 & 1,960 & $0.900^{5}$ & $0.946-0.964$ \\
Lower middle & 27.9 & 1,696 & $0.823^{5}$ & $0.811-0.834$ \\
Bottom & & &
\end{tabular}

\footnotetext{
${ }^{1}$ The model was adjusted by year of calving, season of calving, and parity (see Supplemental Table S1; https:// doi.org/10.3168/jds.2017-13796)

${ }^{2}$ Proportion of cows pregnant by 100 DIM.

${ }^{3}$ Mean milk yield per cow by 80 DIM (CM80) for every quartile of herd milk production by 80 DIM (HM80). ${ }^{4} \mathrm{CM} 80$ at top HM80: effect of 1 SD increase in CM80 over the herd-year mean on the odds of pregnancy at top HM80 (referent). CM80 at upper-middle, lower-middle, and bottom quartiles of HM80: effect of 1 SD increase in CM80 over the herd-year mean on the odds of pregnancy at upper-middle, lower-middle, and bottom quartiles of HM80.

${ }^{5}$ Monte Carlo standard error of odds ratio parameter was $<0.01$.

${ }^{6}$ Effects of upper-middle, lower-middle, and bottom quartiles of herd milk production by 80 DIM (for an average-producing cow) on the odds of pregnancy (reference level = top quartile).
}

in CM80 increased odds of PREG100 by $2.9 \%$ in cows from the bottom quartile of HM80 (OR = 1.029; Table 2). Herd-level milk yield to 80 DIM also had an effect on PREG100 given that an average-producing cow in the upper-middle, lower-middle, or bottom quartile of HM80 had 4.5, 10.0, and 17.7\%, respectively, lower odds of PREG100 compared with an average-producing cow in the top quartile of HM80 (OR $=0.955,0.900$, and 0.823 , respectively; Table 2). The effects of calving year, calving season, and parity are shown in Supplemental Table S1 (https://doi.org/10.3168/jds.2017-13796). In short, the odds of PREG100 decreased as parity increased and were lower in spring-calving cows. Finally, the random effect of the herd explained $4 \%$ of variation in PREG100. The comparison between expected and observed pregnant cows within each ascending decile of fitted values showed that the multilevel logistic model tended to underestimate PREG100 between 0.6 and $2.1 \%$ in all deciles but the highest, where it overestimated by $1.6 \%$.

The effects of CE80 and HE80, adjusted by each other, on the odds of PREG100 are shown in Table 3. Cow-level energy output in milk yield to 80 DIM had a conditional effect on PREG100 given that the odds of being pregnant in cows belonging to a top-quartile herd for HE80 decreased 5.8\% when their CE80 increased $1 \mathrm{SD}$ over the mean of their herd-year $(\mathrm{OR}=0.942$; Table 3). The cross-level interaction between CE80 and HE80 also had an effect on PREG100. The increase of $1 \mathrm{SD}$ in CE80 in cows belonging to upper-middle and lower-middle quartiles of HE80 herds had a negative effect similar to that of cows in the top quartile of HE80 (OR $=0.958$ and 0.987 , respectively; Table 3). Conversely, the same increase in CE80 for cows belonging to herds from the bottom quartile of HE80 had $2.9 \%$ higher odds of PREG100 (OR = 1.029; Table 3). The HE80 also had an effect on PREG100 given that a cow with average energy output in a herd in the upper-middle, lower-middle, or bottom quartiles of HE80 had 6, 8.2, and 9.9\% lower odds of PREG100 compared with an average-producing cow from a topquartile herd for HE80 (OR $=0.940,0.918$, and 0.901, respectively; Table 3 ).

The effect of MTDY, stratified by HM80, on the hazard of pregnancy is shown in Table 4. The effect of MTDY on the hazard of pregnancy showed a negative slope with increasing DIM (Table 4). That is, an increase of 1 SD in MTDY $(8 \mathrm{~kg} / \mathrm{d})$ in cows belonging to top-quartile herds for HM80 showed a lightly negative but nonsignificant effect at 63 DIM [hazard ratio $(\mathbf{H R})=0.987,95 \%$ confidence interval $=0.968-1.007]$, but then it was significantly negative from 84 to 189 DIM (84 DIM: HR $=0.964,95 \%$ confidence interval $=0.944-0.984 ; 189$ DIM: HR $=0.854,95 \%$ confidence interval $=0.821-0.890)$. In cows from bottom-quartile herds for HE80, the effect of a 1 SD increase in MTDY was significantly positive between 63 and 147 DIM (63 DIM: $\mathrm{HR}=1.148,95 \%$ confidence interval $=1.105-$ 1.193; 147 DIM: $\mathrm{HR}=1.043,95 \%$ confidence interval $=1.002-1.086)$, and then that positive effect decreased 
Table 3. Logistic model assessing the effect of milk energy output by 80 DIM at cow and herd levels on the odds of pregnancy by 100 DIM for 657,968 lactations from 677 dairy herds located in Buenos Aires Province, Argentina, over a 12 -yr period $(2001-2012)^{1}$

\begin{tabular}{lcccc}
\hline Item & $\begin{array}{c}\text { PREG100 } \\
(\%)\end{array}$ & $\begin{array}{c}\text { CE80 } \\
(\mathrm{kJ})\end{array}$ & $\begin{array}{c}\text { Odds } \\
\text { ratio }\end{array}$ & $\begin{array}{c}95 \% \text { Credibility } \\
\text { interval }\end{array}$ \\
\hline CE80 by HE80 & & & & \\
CE80 at top & & & $0.942^{5}$ & $0.938-0.945$ \\
CE80 at upper middle & & & $0.987^{5}$ & $0.946-0.970$ \\
CE80 at lower middle & & & $1.029^{5}$ & $0.975-0.999$ \\
CE80 at bottom & 32.2 & 1,737 & 1 & \\
HE80 & 31.3 & 1,525 & $0.940^{5}$ & \\
Top & 31.4 & 1,384 & $0.918^{5}$ & $0.937-0.955$ \\
Upper middle & 29.1 & 1,220 & $0.901^{5}$ & $0.911-0.932$ \\
Lower middle & & & $0.995-0.908$ \\
Bottom & & &
\end{tabular}

${ }^{1}$ The model was adjusted by year of calving, season of calving, and parity (data not shown).

${ }^{2}$ Proportion of cows pregnant by 100 DIM.

${ }^{3}$ Mean of milk energy output per cow by 80 DIM (CE80) for every quartile of herd milk energy output by 80 DIM (HE80).

${ }^{4}$ CE80 at top HE80: effect of 1 SD increase in CE80 over the herd-year mean on the odds of pregnancy at top HE80 (referent). CE80 at upper-middle, lower-middle, and bottom quartiles of HE80: effect of 1 SD increase in CE80 over the herd-year mean on the odds of pregnancy at upper-middle, lower-middle, and bottom quartiles of HE80.

${ }^{5}$ Monte Carlo standard error of odds ratio parameter was $<0.01$.

${ }^{6}$ Effects of upper-middle, lower-middle, and bottom quartiles of herd milk energy output by 80 DIM (for an average cow) on the odds of pregnancy (reference level = top quartile).

to become nonsignificant at 168 DIM $(\mathrm{HR}=1.018$, $95 \%$ confidence interval $=0.974-1.064$; Table 4$)$.

Year of calving had an effect on the hazard of pregnancy (Table 5), and that effect varied through the years. For example, compared with 2012, in 5 yr there was a significant positive effect (from 7 to $11 \%$ increase in the daily risk) for pregnancy, in 5 yr there was no significant difference, and in $1 \mathrm{yr}$ there was a significant negative effect ( $7.1 \%$ decrease in daily risk) on the hazard of pregnancy. In addition, the effect of MTDY was similar through the years 2001 to 2012 (Supplemental Table S2; https://doi.org/10.3168/jds.2017-13796).

Compared with the results obtained with the Cox regression model run on the real data, the sensitivity analysis showed that an increase of 1 SD in MTDY had a greater negative effect on the hazard of pregnancy under complete positive correlation, whereas it had a lower negative effect on the hazard of pregnancy under negative correlation (Supplemental Tables S3 and S4; https://doi.org/10.3168/jds.2017-13796).

\section{DISCUSSION}

The main hypothesis tested in this study was that milk yield and reproductive performance in dairy cows are not necessarily antagonistic and that this relationship is influenced by the effect of the herd. In agreement with our hypothesis, the effect of milk yield on reproductive performance was small and varied with the level of milk yield of the herd. From a practical perspective, multilevel logistic model 1 predicted that when cows belonged to a top-quartile HM80 increased their CM80 by 1 SD over the mean, their PREG100 decreased 1.3 percentage points from 31.4 to $30.1 \%$ [PREG100 risk for average-producing cow $=31.4 \%$ (odds of referent group $=31.4 \% / 1-31.4 \%=0.457$ ); the odds for the exposed group $=0.431$ (odds of reference group $\times 0.942$ ) ; odds to percentage was performed with formula odds/ $(1+$ odds $)]$, whereas with the same increase of $1 \mathrm{SD}$ in $\mathrm{CM} 80$ when cows belonged to a bottom-quartile HM80, their PREG100 increased 0.5 percentage points from 27.9 to $28.4 \%$ (Table 2). Although these effects are statistically significant, their biological effect is almost negligible. Similarly, the Cox regression model predicted that an increase of $1 \mathrm{SD}$ in MTDY over the mean at 84 DIM would decrease pregnancy per 21-d period approximately from $13 \%$ (individual risk of pregnancy for the 21-d period from 84 to 105 DIM; Figure 2) to $12.5 \%$ in a top-quartile HM80 herd $(\mathrm{HR}=0.964$; Table 4$)$, whereas a similar change would increase their pregnancy per 21-d period from 13 to $14.5 \%$ in bottom-quartile HM80 herds (HR $=1.121 ;$ Table 4).

Data validation was based on fulfilling the inclusion criteria. Lack of AI records was the most important reason of exclusion (Figure 3). This could have been caused by farmers' poor record keeping, management decisions such as not breeding low-producing cows, or short or weak estrus expression in high-producing cows. The correlation between herd milk yield and the 
percentage of cows excluded per herd (for reproductive reasons) was $\mathrm{r}=0.139(P<0.001)$, and the mean difference in milk production at $305 \mathrm{~d}$ for included and excluded cows was 7,081 and $6,862 \mathrm{~kg}$, respectively $(P$ $<0.001)$. Despite the small associations between milk yield and excluded cows at herd and cow levels, it is not possible to discard the introduction of selection bias due to the reproductive exclusion criteria used. Despite the limitation imposed by excluding noninseminated cows, we preferred not to introduce more imprecisions in the parameter estimation by assigning an arbitrary pregnancy risk period to those excluded cows.

Multilevel models were designed to incorporate group (herd) context into an individual (cow) model (Snijders and Bosker, 2012). This methodology allowed us to assess the effect of milk yield on pregnancy rate at cow and herd level and the cross-level interaction. Also, considering milk yield as a time-dependent covariate allowed us to estimate the hazard of pregnancy depending on the milk yield closest to each risk period evaluated. It helped us to avoid the bias caused by the negative effect of pregnancy on milk yield, given that only cows not having the event of interest (pregnancy) are used in the hazard estimation at each time point. In addition, using the stratification by quartile of herd production (HM80) and including the interaction between MTDY and HM80 allowed us to test whether the effect of MTDY on the hazard of pregnancy varied across levels of HM80.

Descriptive data analysis showed that reproductive performance had a negative trend over the period of study given that the median of PREG100 was $31 \%$ for 2001 to 2006 versus $27 \%$ for 2007 to 2012 . At the same time, milk yield had a positive trend, with 305-d milk yield (MY305) of 6,656 $\mathrm{kg}$ for 2001 to 2006 versus 7,557 kg for 2007 to 2012 (Table 1; Figure 1). Although these 2 situations occurred concurrently and an apparent antagonism could be suspected, the effect of milk

Table 5. Effect of calving year on the hazard of pregnancy, adjusted by daily cow milk yield, season of calving, and parity for 94,593 lactations from 402 dairy herds located in Buenos Aires Province, Argentina

\begin{tabular}{lcc}
\hline Year & Hazard ratio & $95 \% \mathrm{CI}$ \\
\hline 2001 & 1.076 & $1.010-1.146$ \\
2002 & 1.082 & $1.025-1.142$ \\
2003 & 1.055 & $0.999-1.113$ \\
2004 & 1.116 & $1.061-1.175$ \\
2005 & 1.085 & $1.029-1.144$ \\
2006 & 1.112 & $1.060-1.167$ \\
2007 & 1.010 & $0.961-1.062$ \\
2008 & 1.033 & $0.981-1.087$ \\
2009 & 1.014 & $0.964-1.066$ \\
2010 & 0.982 & $0.934-1.032$ \\
2011 & 0.929 & $0.882-0.978$ \\
2012 & 1 & Referent \\
\hline
\end{tabular}


yield on the hazard of pregnancy was almost constant throughout the study (Supplemental Table S2; https:// doi.org/10.3168/jds.2017-13796). Taking all the above information together, we could speculate that other variables might have concomitantly changed with the increase in milk yield, and that could be affecting the fertility outcome. Also, our finding that average cows from top-producing herds had better reproductive performance than average cows from low-producing herds could suggest that, among all the herd-level factors explaining this result, the managers' ability to meet their cows' needs for high milk yield also supports good fertility.

As the proportional hazards assumption was violated, an interaction term (MTDY by DIM) was included in the Cox model as suggested by Allison (1995). In survival analysis for reproductive data, main effects (i.e., MTDY) on the hazard of events (i.e., pregnancy) are estimated for all the individuals at the start of the risk period, but as time progresses these main effects on the hazards are estimated on a subpopulation that is less likely to experience the event of interest. This could help explain our finding that a significant negative effect of MTDY on the hazard of pregnancy was detected only in high-milk-yield herds specifically toward the end of the risk period. This finding does not seem to make biological sense because peak milk yield and negative energy balance take place early in lactation. Therefore, our speculation is that in a subfertile population the effect of daily milk yield on the hazard of pregnancy would be constant through all the risk period but that the theoretical negative effect would be masked by a possible positive effect of MTDY on the hazard of pregnancy in the more fertile population present at the beginning of the risk period.

Regarding sensitivity analysis, we asked whether censored cows had the same future frequency of pregnancy as cows not censored. From the sensitivity analysis results shown in Supplemental Tables S3 and S4 (https:// doi.org/10.3168/jds.2017-13796), we can see that under both hypothetical scenarios the effect of MTDY on the hazard of pregnancy was more marked but remained in the same direction, suggesting that the violation of nonindependent censoring is not a big concern in this case. This slightl reduction in the size effect of MTDY could be explained by the fact that the frequency of lower producers is greater than that of higher producers in the censored subpopulation (indicative of culling). In this sense, it has been observed that milk production acts as a protective factor for cow culling risk in commercial herds (Morton, 2006).

Published reports evaluating the relationship between milk yield and reproductive performance have shown divergent results. Bello et al. (2013) reported no antagonism between daily milk yield at first postpartum insemination and pregnancy at first AI at the cow level, but this antagonism appeared at herd level, especially in herds with good fertility (i.e., $50 \%$ herd probability of pregnancy at first AI). The same researchers (Bello et al., 2012) had previously found a negative effect at the cow level (calving to conception interval increased by $0.51 \mathrm{~d}$ per increase of $100 \mathrm{~kg}$ in MY305) but a positive effect at herd level (calving to conception interval decrease of $1.37 \mathrm{~d}$ per increase of $100 \mathrm{~kg}$ in herd MY305). These discrepancies could be explained by the indicators of milk yield and fertility used (short term vs. long term). Piccardi et al. (2013) found that cows belonging to the top tercile of intraherd milk yield had a lower hazard of pregnancy than cows from the bottom tercile of milk yield. The difference between the findings of Piccardi et al. (2013) and ours could be explained by the fact that the herds were from different regions of Argentina with different production systems, by the different time periods involved [1 yr vs. 12 yr (ours)], and especially by the way the effect of the herd was analyzed. Piccardi et al. (2013) categorized individual milk yield (MY305) into intraherd terciles without assessing whether that effect varied across the different levels of productivity of herds. Because the previous studies used MY305, this could have overestimated the negative effects of milk yield on reproductive performance due to the effects of pregnancy on milk yield.

In multilevel logistic model 2, we used $\mathrm{NE}_{\mathrm{L}}$ (i.e., CE80) to explain the odds of PREG100. We found that an increase of $1 \mathrm{SD}$ in CE80 was associated with a $5.8 \%$ decrease in PREG100 for cows in a top-quartile herd for HE80 and that the same increase in CE80 was related to a $2.9 \%$ increase in PREG100 in herds in the bottom quartile of HE80 (Table 3). This finding is similar to what we obtained with raw milk yield as the predictor in model 1 . Therefore, we propose that the reported negative effect of negative energy balance on fertility would not be explained by the increased demand of energy to support milk yield. This supports the notion that the effect of energy balance on fertility would have more to do with the amount of net energy consumed than with the amount of net energy secreted in milk.

One of the limitations of our work is that the data set lacks information about possible confounder variables such as disease and intervening variables such as energy balance. Despite that, our approach is valid to test for the existence of an antagonistic association between milk yield and fertility at cow and herd levels and how these associations varied during a $12-y r$ period. The main conclusions of the present work are that the magnitude of the relationship between milk yield and 
reproductive performance is small and that it depends on the level of herd production.

\section{ACKNOWLEDGMENTS}

This study was partially financed by the Asociación de la Regional Pampeana de Entidades de Control Lechero (ARPECOL; La Plata, Argentina) and by Universidad Nacional de La Plata (La Plata, Argentina) grant V11/230 to R. L. de la Sota. Ramiro Rearte had a scholarship from Consejo Nacional de Investigaciones Científicas y Técnicas (Buenos Aires, Argentina) and from Government of Canada, through the Department of Foreign Affairs, Trade and Development Canada (DFATD) in the framework of Emerging Leaders in the Americas program (ELAP), Ottawa, Canada. The authors acknowledge the great cooperation of Juan Carlos Galassi and Alberto Miranda from ARPECOL.

\section{REFERENCES}

Allison, P. D. 1995. Survival Analysis Using SAS: A Practical Guide. SAS Institute Inc., Cary, NC.

Bello, N. M., J. S. Stevenson, and R. J. Tempelman. 2012. Invited review: Milk production and reproductive performance: Modern interdisciplinary insights into an enduring axiom. J. Dairy Sci. 95:5461-5475.

Bello, N. M., J. P. Steibel, R. J. Erskine, and R. J. Tempelman. 2013. Cows and herds constitute distinct hierarchical levels of heterogeneity in the variability of and association between milk yield and pregnancy outcome in dairy cows. J. Dairy Sci. 96:2314-2326.

Borucka, J. 2013. Extensions of Cox model for non-proportional hazards purpose. Accessed Nov. 15, 2016. https://www.lexjansen .com/phuse/2013/sp/SP07.pdf.

Butler, W. R. 2003. Energy balance relationships with follicular development, ovulation and fertility in postpartum dairy cows. Livest. Prod. Sci. 83:211-218.

Campbell, M. S., K. Hand, D. F. Kelton, F. Miglior, and S. J. LeBlanc. 2009. The association of level of milk production with reproductive performance. J. Dairy Sci. 92(E-Suppl. 1):335. (Abstr.)

Cook, J. G., and M. J. Green. 2016. Use of early lactation milk recording data to predict the calving to conception interval in dairy herds. J. Dairy Sci. 99:4699-4706.

Eicker, S. W., Y. T. Grohn, and J. A. Hertl. 1996. The association between cumulative milk yield, days open, and days to first breeding in New York Holstein cows. J. Dairy Sci. 79:235-241.

FAO (Food and Agriculture Organization of the United Nations). 2005. Global dairy sector: Status and trends. Accessed Sep. 15, 2016. http://www.fao.org/docrep/012/i1522e/i1522e02.pdf.

Green, M. J., P. R. Burton, L. E. Green, Y. H. Schukken, A. J. Bradley, E. J. Peeler, and G. F. Medley. 2004. The use of Markov chain Monte Carlo for analysis of correlated binary data: Patterns of somatic cells in milk and the risk of clinical mastitis in dairy cows. Prev. Vet. Med. 64:157-174.
Gröhn, Y. T., and P. J. Rajala-Schultz. 2000. Epidemiology of reproductive performance in dairy cows. Anim. Reprod. Sci. 60-61:605614.

ISO. 1999. Whole milk-Determination of milk fat, protein and lactose content-Guidance on the operation of mid-infrared instruments. The International Organization for Standarization (ISO), Geneva, Switzerland. Accessed Sep. 17, 2016. https://www.iso.org/ standard/17436.html.

LeBlanc, S. 2010. Assessing the association of the level of milk production with reproductive performance in dairy cattle. J. Reprod. Dev. 56:S1-S7.

Lin, D. Y., and L. J. Wei. 1989. The robust inference for the Cox proportional hazard model. J. Am. Stat. Assoc. 84:1074-1078.

Lucy, M. C. 2001. Reproductive loss in high-producing dairy cattle: Where will it end? J. Dairy Sci. 84:1277-1293.

Madouasse, A., J. N. Huxley, W. J. Browne, A. J. Bradley, I. L. Dryden, and M. J. Green. 2010. Use of individual cow milk recording data at the start of lactation to predict the calving to conception interval. J. Dairy Sci. 93:4677-4690.

Melendez, P., and P. Pinedo. 2007. The association between reproductive performance and milk yield in Chilean Holstein cattle. J. Dairy Sci. 90:184-192.

Miller, R. H., H. D. Norman, M. T. Kuhn, J. S. Clay, and J. L. Hutchison. 2007. Voluntary waiting period and adoption of synchronized breeding in dairy herd improvement herds. J. Dairy Sci. 90:1594-1606.

Morton, J. M. 2006. Potential bias in observed associations between milk yield and reproductive performance in dairy cows. Page 1092 in Proc. 11th International Symposium on Veterinary Epidemiology and Economics, Cairns, Queensland. International Symposia on Veterinary Epidemiology and Economics Proceedings.

Parellada, G., and E. Schilder. 1999. Seasonal and cyclical changes in dairy industry in Argentina. Feb. 1, 2017. http://inta.gob.ar/sites/ default/files/script-tmp-dt_04.pdf.

Piccardi, M., A. C. Funes, M. Balzarini, and G. A. Bo. 2013. Some factors affecting the number of days open in Argentinean dairy herds. Theriogenology 79:760-765.

Rajala-Schultz, P. J., W. J. A. Saville, G. S. Frazer, and T. E. Wittum. 2001. Association between milk urea nitrogen and fertility in Ohio dairy cows. J. Dairy Sci. 84:482-489.

RAP. 1999. Food and Nutrition Tables for Ruminants. 4th ed. Swiss Federal Research Station for Animal Production (RAP). Swiss Federal Research Institute for Livestock, Posieux, Switzerland.

Rasbash, J., C. Charlton, W. J. Browne, M. Healy, and B. Cameron. 2009. MLwiN. Version 2.10. Centre for Multilevel Modelling, University of Bristol, UK.

Sargent, F. D., V. H. Lytton, and O. G. Wall. 1968. Test interval method of calculating Dairy Herd Improvement Association records. J. Dairy Sci. 51:170-179.

SAS. 2016. SAS and STAT User's Guide. Release 9.4. SAS Institute Inc., Cary, NC.

Snijders, T. A. B., and R. J. Bosker. 2012. Multilevel Analysis: An Introduction to Basic and Advanced Multilevel Modeling. 2nd ed. Sage, London, UK.

Taverna, M. 2013. An analysis of the evolution of milk production systems in Argentina. Accessed Nov. 15, 2016. http://www.maa .gba.gov.ar/2010/SubPED/Ganaderia/archivos/9_DE_JULIO _Miguel_Taverna.pdf.

WinEpi. 2006. Working in epidemiology. Accessed Jun. 30, 2016 http://www.winepi.net. 